\title{
Gene expression profiling of the green seed problem in Soybean
}

\author{
Renake N. Teixeira ${ }^{1,2^{*}}$, Wilco Ligterink ${ }^{1}$, José de B. França-Neto ${ }^{3}$, Henk W.M. Hilhorst ${ }^{1}$ and Edvaldo A. A. da Silva ${ }^{2}$
}

\begin{abstract}
Background: Due to the climate change of the past few decades, some agricultural areas in the world are now experiencing new climatic extremes. For soybean, high temperatures and drought stress can potentially lead to the "green seed problem", which is characterized by chlorophyll retention in mature seeds and is associated with lower oil and seed quality, thus negatively impacting the production of soybean seeds.

Results: Here we show that heat and drought stress result in a "mild" stay-green phenotype and impaired expression of the STAY-GREEN 1 and STAY-GREEN 2 (D1, D2), PHEOPHORBIDASE 2 (PPH2) and NON-YELLOW COLORING 1 (NYC1_1) genes in soybean seeds of a susceptible soybean cultivar. We suggest that the higher expression of these genes in fully mature seeds of a tolerant cultivar allows these seeds to cope with stressful conditions and complete chlorophyll degradation.

Conclusions: The gene expression results obtained in this study represent a significant advance in understanding chlorophyll retention in mature soybean seeds produced under stressful conditions. This will open new research possibilities towards finding molecular markers for breeding programs to produce cultivars which are less susceptible to chlorophyll retention under the hot and dry climate conditions which are increasingly common in the largest soybean production areas of the world.
\end{abstract}

Keywords: Chlorophyll retention, Differential expression, Drought stress, Green seeds, Heat stress, Seed quality

\section{Background}

Chlorophyll (Chl) retention in mature soybean seeds is a major problem for Brazilian soybean growers. If more than $9 \%[1]$ of their harvest shows this phenotype, marketability will be compromised, resulting in serious financial losses. The "green seed problem" has been reported in oilseeds since the early 1990s, i.e. as detrimental to soybean seed and oil quality [1-3] and to canola oil quality [4-7].

Retention of Chl in soybean seeds is mainly associated with low rainfall and high temperatures during the maturation phase. These are common environmental conditions in tropical areas such as the Brazilian cerrado biome where approximately $45 \%$ of the Brazilian soybean seed production is concentrated (14.5 million

\footnotetext{
* Correspondence: renakent@gmail.com

${ }^{1}$ Wageningen Seed Lab, Laboratory of Plant Physiology, Wageningen

University, Droevendaalsesteeg 1, Wageningen 6708 PB, The Netherlands

${ }^{2}$ Departamento de Produção e Melhoramento Vegetal, Faculdade de

Ciências Agronômicas-UNESP, Universidade Estadual Paulista, Botucatu, SP

18.610-307, Brazil

Full list of author information is available at the end of the article
}

hectares) [8]. Besides the climate, other factors or practices during pre- and post-harvesting, such as application of desiccants and premature harvesting followed by drying at high temperatures are also reported to result in retention of chlorophyll in soybean seeds [2]. In addition to these environmental factors there is also variation in the susceptibility of soybean cultivars to green seed production under stress. The cultivar BRS 133 has been previously described as tolerant, producing less green seeds under stressful conditions whereas MG/ BR 46 was found to be more susceptible [9].

During leaf senescence, the first observable change is yellowing of green tissues. Yellowing is also observed during normal seed maturation which is expected to be a degreening process resulting from the conversion of Chl into colourless products in a multi-step catabolic pathway similar to that described for leaf senescence [10-12]. Leaf senescence has been extensively studied and mutant lines exhibiting altered leaf senescence have been described for several different species e.g. Arabidopsis, rice, Medicago and soybean. These mutant lines 
are commonly known as stay green (SGR) mutants [13-25]. However, in contrast to leaf senescence, very little is known about Chl degradation in developing and maturing seeds. Degreening in maturing seeds cannot be considered senescence but both leaf senescence and seed maturation require $\mathrm{Chl}$ degradation for their completion.

In leaves $\mathrm{Chl}$ degradation occurs in the chloroplast and requires six known Chl-catabolic enzymes (CCEs) and a metal-chelating substance (MCS) that remains to be identified [26]. The breakdown starts with the twostep reduction of $\mathrm{Chl} b$ to $\mathrm{Chl} \mathrm{a}$, catalysed by $\mathrm{Chl} b$ reductase and 7-hydroxymethyl $\mathrm{Chl} a$ reductase (HCAR) [27]. In the next step the central $\mathrm{Mg}^{2+}$ ion of Chl is removed by an unknown MCS to yield a Mg-free Chl intermediate known as pheophytin $a$ (Phein $a$ ). Subsequently, pheophytinase (PPH), catalyses the hydrolysis of Phein $a$ to produce pheophorbide a (Pheide $a$ ) [22, 28]. The chlorin macrocycle of Pheide $a$ is oxygenolytically opened by Pheide $a$ oxygenase (PAO) [14], and the product of this reaction, red $\mathrm{Chl}$ catabolite $(\mathrm{RCC})$, is reduced to a non-phototoxic primary fluorescent $\mathrm{Chl}$ catabolite (pFCC) by RCC reductase (RCCR) [29]. Thereafter, $\mathrm{pFCC}$ is transferred to the cytosol and stored in vacuoles as non-fluorescent Chl-catabolite $[10,11,20,26]$

In addition to CCEs and MCS, the SGR protein acts as a key regulator of Chl degradation. $S G R$ is a nuclear gene encoding a chloroplast targeted protein, and its homologs exist as either single or duplicated genes in higher plants [16]. Most higher plant species have two or more SGR homologs (STAY-GREEN - SGR and STAY-GREEN LIKE - SGRL), all of which are predicted to localize to the chloroplast [16,30]. In a recent study, phylogenetic analysis suggested that the soybean genes, Glyma11g02980 and Glyma01g42390, are homologs of PsSGR, AtNYE1, AtNYE2, and OsSGR [17]. These genes were named D1 (Glyma01g42390) and D2 (Glyma11g02980) and described in soybean as two unlinked, paralogous nuclear genes, whose double-recessive mutant $(d 1 d 1 d 2 d 2)$ results in $\mathrm{Chl}$ retention in soybean leaves and seeds [17].

The increase of environmental stress over the past decades is a growing concern worldwide especially for agricultural productivity. Efforts have already been made to understand the influence of growing conditions and drying processes on the retention of green pigments in soybean seeds and how it affects the physiological and biochemical characteristics of these seeds [2, 3, 9, 31, 32]. So far, the molecular mechanisms of Chl degradation in seeds and consequently of Chl retention remain unsolved. In this study we have used maturing seeds of two soybean cultivars differing in susceptibility to stress-induced $\mathrm{Chl}$ retention to investigate the molecular basis of chlorophyll retention in seeds. A global gene expression approach was performed in association with targeted gene expression analysis (RT-qPCR) to demonstrate that the green phenotype in stressed soybean seeds is related to impaired expression of chlorophyll catabolic genes (CCGs), stay-green genes and also of some photosynthetic proteins. Our results contribute both to the understanding of the physiological underpinning of Chl degradation in seeds and to the identification of possible breeding targets for future soybean improvement.

\section{Results}

\section{Chlorophyll content in maturing soybean seeds}

Plants of susceptible and tolerant soybean cultivars were grown under non-stressed conditions and during the late seed maturation phase some plants were transferred to a condition of combined heat and drought stress. Seeds of both cultivars (matured under stressed and non-stressed conditions) were harvested in three stages of maturation (R6, R7 and R8) according to a scale proposed by SW Ritchie, JJ Hanway and HE Thompson [33] (Additional file 1: Table S1). R6 seed samples (stressed and nonstressed) were considered "green" if there was no sign of Chl degradation and they were still completely green. At R6 there were no appreciable differences in Chl degradation between the different cultivars and between environmental conditions (Fig. 1). At R7, when Chl degradation should have started, the greenish seeds were considered "green". At this stage there was an expected decrease in percentage of green seeds due to normal chlorophyll degradation during maturation but no significant difference was observed between cultivars or environmental conditions (Fig. 1). At R8, when seeds should be yellow and the presence of $\mathrm{Chl}$ is a potential problem for seed quality, any sign of green pigmentation classified seeds as "green", characterizing chlorophyll retention. At this stage, the susceptible cultivar produced, under stress, a significantly higher level of green seeds, reaching $22 \%$ of green seeds against $1 \%$ produced by the tolerant cultivar (Figs. 1 and 2). For more accuracy in determining the Chl retention in stressed soybean seeds, $\mathrm{Chl} a$ and $\mathrm{Chl} b$ were measured by HPLC (Fig. 3).

As expected, the chlorophyll content decreased during maturation of both cultivars, independently of the environmental condition. Chl $a$ was present at higher levels in the seeds than Chl $b$. The effect of stress on seed chlorophyll content was variable depending on the cultivar and stage of maturation. At R8, when the presence of chlorophyll is a problem, there was only difference between stressed and non-stressed seeds of the susceptible cultivar and the levels of Chl $a$ and $b$ in stressed seeds of this cultivar were significantly higher than in stressed 

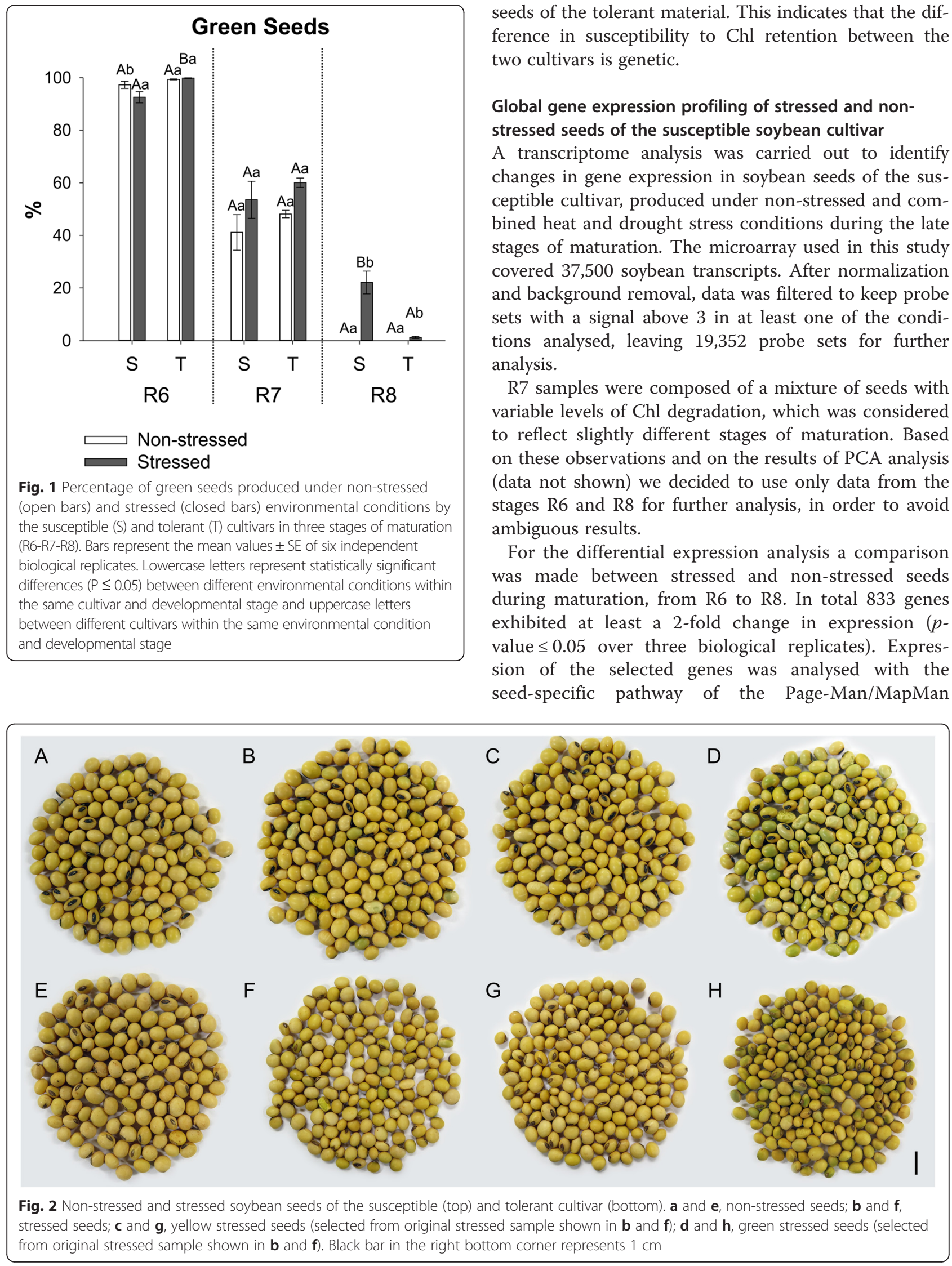

seeds of the tolerant material. This indicates that the difference in susceptibility to Chl retention between the two cultivars is genetic.

\section{Global gene expression profiling of stressed and non-} stressed seeds of the susceptible soybean cultivar

A transcriptome analysis was carried out to identify changes in gene expression in soybean seeds of the susceptible cultivar, produced under non-stressed and combined heat and drought stress conditions during the late stages of maturation. The microarray used in this study covered 37,500 soybean transcripts. After normalization and background removal, data was filtered to keep probe sets with a signal above 3 in at least one of the conditions analysed, leaving 19,352 probe sets for further analysis.

R7 samples were composed of a mixture of seeds with variable levels of $\mathrm{Chl}$ degradation, which was considered to reflect slightly different stages of maturation. Based on these observations and on the results of PCA analysis (data not shown) we decided to use only data from the stages R6 and R8 for further analysis, in order to avoid ambiguous results.

For the differential expression analysis a comparison was made between stressed and non-stressed seeds during maturation, from R6 to R8. In total 833 genes exhibited at least a 2 -fold change in expression ( $p$ value $\leq 0.05$ over three biological replicates). Expression of the selected genes was analysed with the seed-specific pathway of the Page-Man/MapMan 


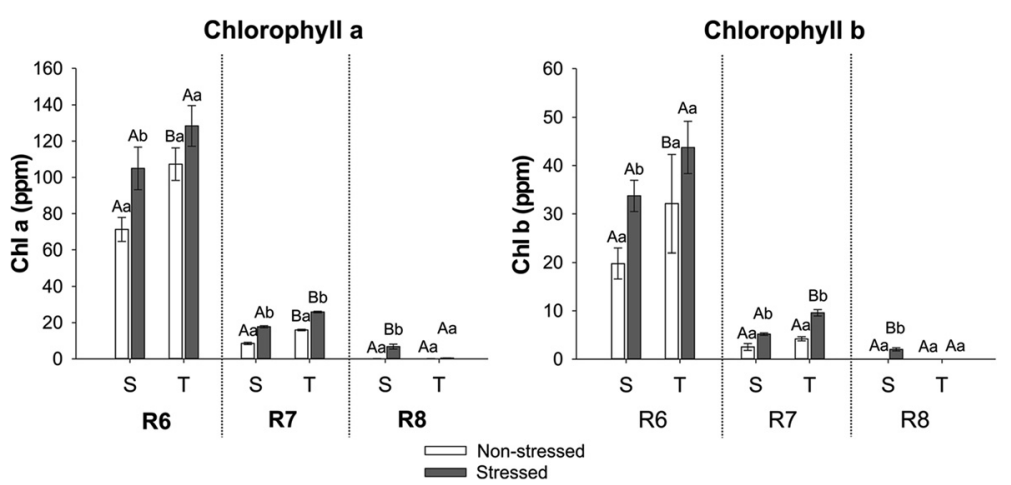

Fig. $3 \mathrm{Chl} a$ and $b$ content of soybean seed samples produced under non-stressed (open bars) and stressed (closed bars) environmental condition by the susceptible (S) and tolerant (T) cultivars in three stages of maturation (R6-R7-R8). Bars represent the mean values \pm SE of three independent biological replicates. Lowercase letters represent statistically significant differences ( $P \leq 0.05)$ between different environmental conditions within the same cultivar and developmental stage and uppercase letters between different cultivars within the same environmental condition and developmental stage

package (http://MapMan.gabipd.org). This pathway efficiently captures the most relevant molecular processes in seeds (Fig. 4) [34] and it allows a global overview of the ontologies of the up- and down-regulated genes in stressed seeds, during the maturation process.

In the seed-specific pathways multiple ontologies were enriched. As was expected, the stress significantly changed expression of genes related to a large number of different cell functions. For example, photosynthesis, transcription factors such as AP2/EREBP, minor $\mathrm{CHO}$ (reserve), DNA repair/synthesis, cell wall modification, seed storage proteins, flavonoids (secondary metabolism), lipid transfer proteins and GA metabolism were among the up-regulated pathways. Genes related to TCA, nucleotide degradation and RNA binding, transcription and processing were down regulated as compared to non-stressed seeds.

We focused on genes related to photosynthesis and to genes encoding enzymes involved in the Chl degradation pathway, because our aim was to find genes related to $\mathrm{Chl}$ retention in soybean seeds. Expression of selected candidate genes were further studied using RTqPCR analysis, comparing stressed and non-stressed seeds of the two soybean cultivars at R6 and R8 maturation stages.

\section{Expression analysis of $\mathrm{Chl}$ binding proteins in stressed and non-stressed soybean seeds}

Chl degradation during leaf senescence is coupled to degradation of the Chl-protein complexes found in the thylakoid membrane, including PSI, PSII and cytochrome $\mathrm{B}_{6} \mathrm{~F}[20,24,35]$. Although we did not measure accumulation/degradation of the Chl-protein complexes, the expression of genes encoding for such proteins during the maturation process of stressed and non-stressed soybean seeds, can give us an idea of what happens with the photosystems and more specifically with the apoproteins that bind Chls.

The chosen transcripts represent some of the genes encoding for Chl-binding proteins, playing roles in photosystem I (LHCA, psaA, psaB), photosystem II ( $p s b A, p s b B, p s b C, p s b D)$ and cytochrome $\mathrm{B}_{6} \mathrm{~F}\left(C y t B_{6} F\right)$. The expression of $C y t B_{6} F, L H C A$ and $p s b B$ was higher in stressed than non-stressed seeds of the susceptible cultivar in R8 and there was significant difference in expression between stressed seeds of the susceptible cultivar and stressed seeds of the tolerant one. However, the expression of $p s b C$ was higher in stressed seeds of both cultivars in R8 (Fig. 5). $p s b A$ and $p s b D$ are genes encoding for the core proteins of PSII (D1 and D2 proteins, respectively). Expression of both genes towards the end of maturation (R8), was higher in stressed seeds of both cultivars. However, expression of $p s b A$ was significantly higher in stressed seeds of the susceptible cultivar compared to stressed seeds of the tolerant one while expression of $p s b D$ was higher in non-stressed seeds of the tolerant cultivar than in non-stressed seeds of the susceptible cultivar (Fig. 6). As the core subunits of PSI also bind $\mathrm{Chl}$, the expression of the genes $p s a A$ and $p s a B$ encoding for the proteins A1 and A2 (respectively), was also analysed. At R8, expression of $p s a A$ was higher only in stressed seeds of the susceptible cultivar, while for $p s b B$ the expression was higher in stressed seeds of both cultivars (Fig. 6).

\section{Expression of CCGs in stressed and non-stressed soybean seeds}

To better understand the breakdown of Chl in soybean seeds and, consequently, its retention, we analysed the expression of some of the genes encoding for enzymes in the Chl degradation pathway. Among the ten CCGs tested by RT-qPCR in the present study, NYC1_1 and 


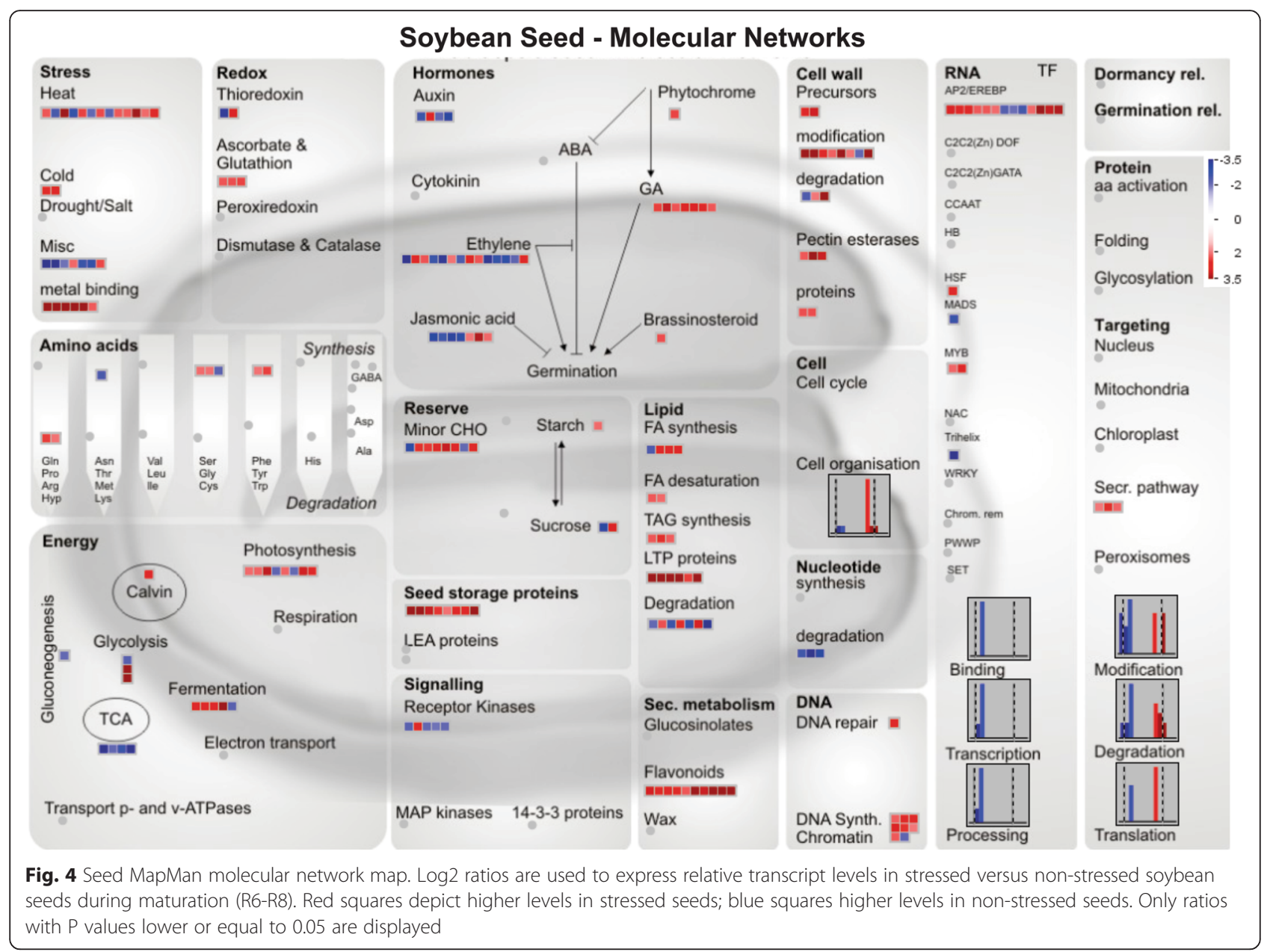

$P P H 2$ were the most affected by stress and most likely to be related to Chl retention (Fig. 7).

The first step in Chl degradation is the conversion of Chl $b$ to Chl $a$ which is catalysed by Chl $b$ reductase. Defects in the synthesis of this enzyme are known to cause Chl retention in leaves of rice non-yellow colouring 1 (nyc1) mutants during senescence [20, 24]. The expression of two transcripts encoding for $\mathrm{Chl} b$ reductase (NYC1_1 - Glyma07g09430 and NYC1_2 - Glyma09g32370) was analysed. Although $N Y C 1 \_2$ is higher expressed in stressed seeds of both cultivars in R8 (Fig. 7), Chl $b$ is still present in stressed seeds of the susceptible cultivar at the end of the maturation (Fig. 3). However, expression of NYC1_1 is only higher in stressed seeds of the tolerant cultivar (Fig. 7), which could explain why mature seeds of this cultivar don't contain Chl $b$ (Fig. 3). This suggests that expression of both copies of NYC1 might be necessary for complete conversion of Chl $b$ to $a$ in seeds of soybean.

Chl breakdown continues with the removal of $\mathrm{Mg}^{2+}$ and phytol by MCS and PPH/Chlorophyllases (CLH), resulting in Pheide $a$. The expression of four genes coding for CLH was analysed by RT-qPCR, but only one of them was expressed in the analysed samples (Glyma10g00570). The transcript level of this $C L H$ gene was higher in stressed seeds of the susceptible cultivar in R8 both as compared to its non-stressed seeds as to the stressed seeds of the tolerant one. There was no difference between stressed and non-stressed seeds of the tolerant cultivar (Fig. 7). Despite these results, stressed mature seeds of the susceptible cultivar didn't completely degrade the Chl (Figs. 2 and 3). As a result, no correlation was found between $C L H$ expression and chlorophyll content (Fig. 10).

The mechanism of Mg-dechelation has not yet been fully resolved [10]. CLH, which hydrolyses phytol from Chl, was believed to be active during senescence-related $\mathrm{Chl}$ breakdown [36, 37]. However, so far CLH action has been classified as essential or not essential, depending on the species. The double mutant of AtCLH1 and AtCLH2 in Arabidopsis did not generate a stay-green phenotype [38] which suggested that $C L H$ might not play a major role in Chl degradation during leaf senescence in Arabidopsis [20, 38]. Instead, the functional characterization of $P P H$ has 
Cyt $B_{6} F$

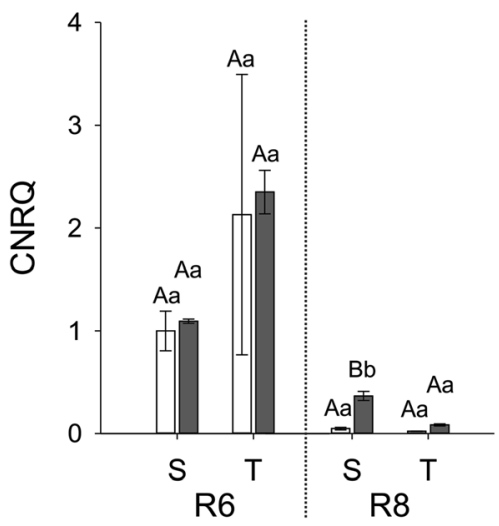

psbB

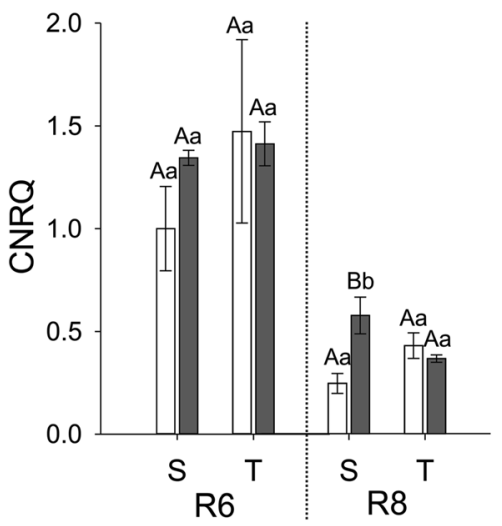

LHCA

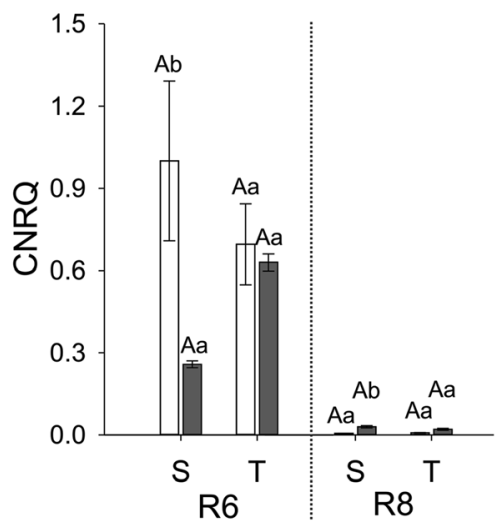

psbC

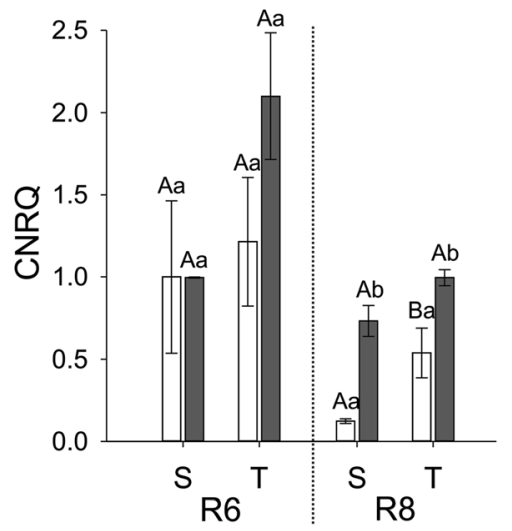

$\square$ Non-stressed

Stressed

Fig. 5 Gene expression analysis by real-time quantitative PCR represented as the calibrated normalized relative quantity (CNRQ) for Cyt B6F, $L H C A$, psbB and psbC. Gene expression is shown for non-stressed (open bars) and stressed seeds (closed bars) of the susceptible (S) and tolerant (T) cultivars in three stages of maturation (R6-R7-R8). Bars represent the mean values \pm SE of three independent biological replicates. Lowercase letters represent statistically significant differences $(P \leq 0.05)$ between different environmental conditions within the same cultivar and developmental stage and uppercase letters between different cultivars within the same environmental condition and developmental stage

indicated that this enzyme is necessary for Chl breakdown in Arabidopsis [22] and rice [20].

The analysis of $P P H$ expression in our seed samples indicates that pheophytinases may play a major role in dephytylation in seeds. The expression of PPH1 (Glyma09g36010) and PPH3 (Glyma12g01320) decreased during maturation, while PPH2 (Glyma11g16070) increased (Fig. 7). PPH2 expression seems to be required later in maturation, especially in stressed seeds of the tolerant cultivar. The expression of this gene was significantly higher in stressed seeds of the tolerant cultivar than in stressed seeds of the susceptible one. PPHs seem to be playing a major role in phytol removal in soybean seeds produced under stress, as stressed seeds of the tolerant cultivar do not retain greenness to the same extent as stressed seeds of the susceptible one (Fig. 7).
Downstream of the degradation pathway, after Phein $a$ is converted by $\mathrm{PPH}$ to Pheide $a$, this intermediate is subsequently converted to the red-coloured molecule $\mathrm{RCC}$ in a reaction mediated by PAO. The expression of two genes encoding for PAO was analysed: PAO1 (Glyma11g19800) and PAO2 (Glyma12g08740). Both genes were higher expressed in stressed seeds of the susceptible and tolerant cultivars mainly in R8, but the expression of PAO1 was higher in both stressed and nonstressed seeds of the tolerant cultivar than in stressed and non-stressed seeds of the susceptible cultivar (Fig. 8). In the next step of Chl degradation, the red pigment $(\mathrm{RCC})$ is converted to the non-coloured but blue-fluorescing product called primary fluorescent chlorophyll catabolite by RCCR. The primary fluorescent chlorophyll catabolite is further converted to non- 

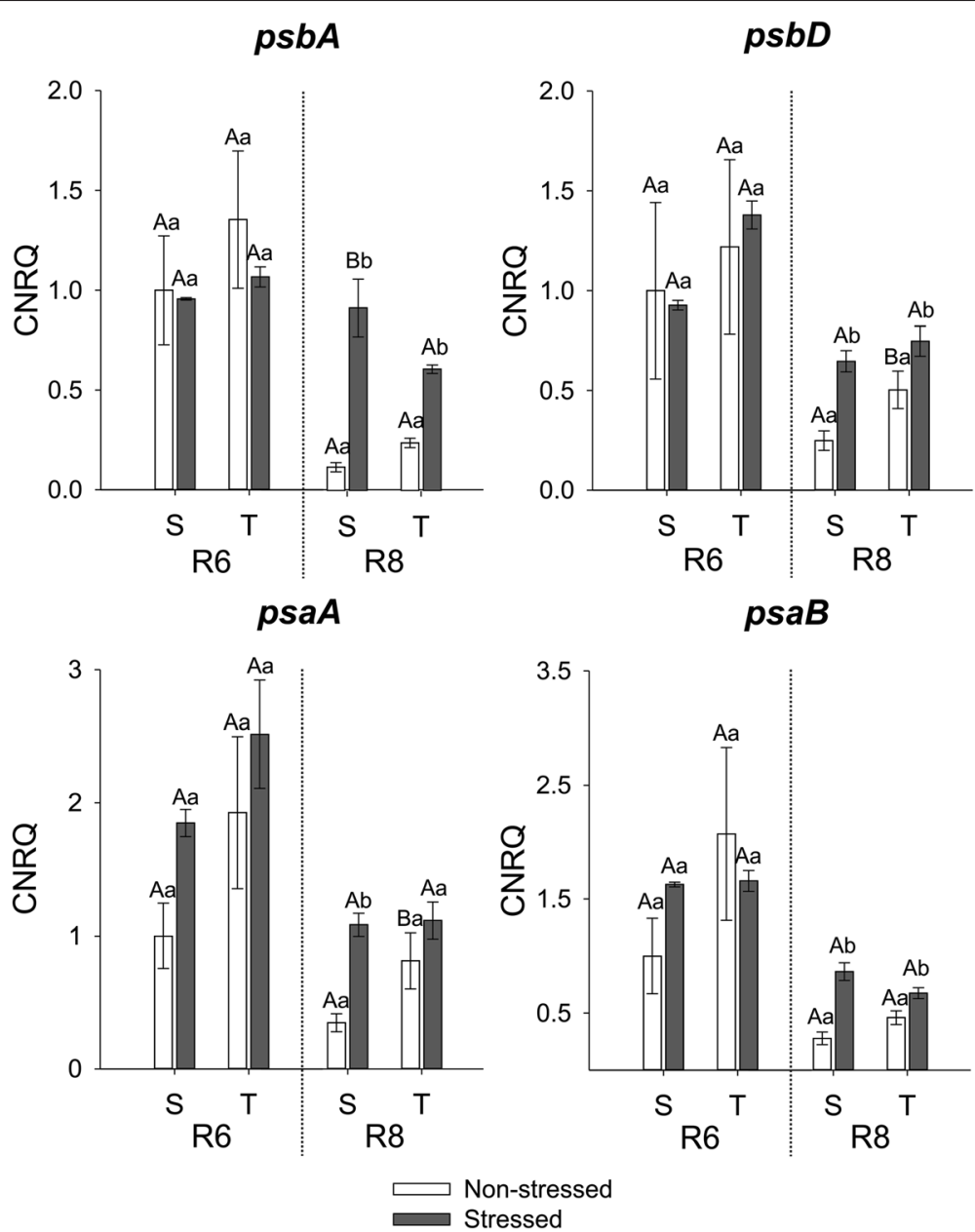

Fig. 6 Gene expression analysis by real-time quantitative PCR represented as the calibrated normalized relative quantity (CNRQ) for $p s b A$, psbD, psaA and psaB. Gene expression is shown for non-stressed (open bars) and stressed seeds (closed bars) of the susceptible ( $\mathrm{S}$ ) and tolerant ( $\mathrm{T}$ ) cultivars in three stages of maturation (R6-R7-R8). Bars represent the mean values \pm SE of three independent biological replicates. Lowercase letters represent statistically significant differences ( $\mathrm{S} \leq 0.05)$ between different environmental conditions within the same cultivar and developmental stage and uppercase letters between different cultivars within the same environmental condition and developmental stage

fluorescent Chl-catabolites through different mechanisms depending on the species. The expression of RCCR1 (Glyma14g01620) in R8 was lower in stressed than non-stressed seeds of the susceptible cultivar (Fig. 8). Also the level of expression was lower for both stressed and non-stressed seeds of the tolerant cultivar when compared with seeds of the susceptible one produced in R8. Independently of cultivar or stage of maturation, there was no difference in expression of $R C C R 2$ as result of the stresses applied (Fig. 8).

\section{Stay-green gene expression is impaired in stressed/green seeds}

The expression of both D1 (Glyma01g42390) and D2 (Glyma11g02980) in soybean seeds increased during the progression of seed maturation, with higher levels in R8 (Fig. 9). In R8 the expression of both genes was higher in stressed than non-stressed seeds only of the tolerant cultivar which exhibited consistently higher expression levels of both genes when compared with the susceptible cultivar.

In general, most of the genes analysed follow a pattern of decreased expression together with a decrease in chlorophyll content during seed maturation, except for NYC1_1 and 2, PPH2, D1 and D2. In the correlation analysis (Fig. 10) it is evident that only expression of D1, D2, NYC1_1 and PPH2 showed a significant negative correlation with chlorophyll content, while all the other genes were either positively correlated or showed no correlation with chlorophyll content.

\section{Discussion}

For over a decade Brazilian soybean growers have been reporting the occurrence of green seeds at the end of 


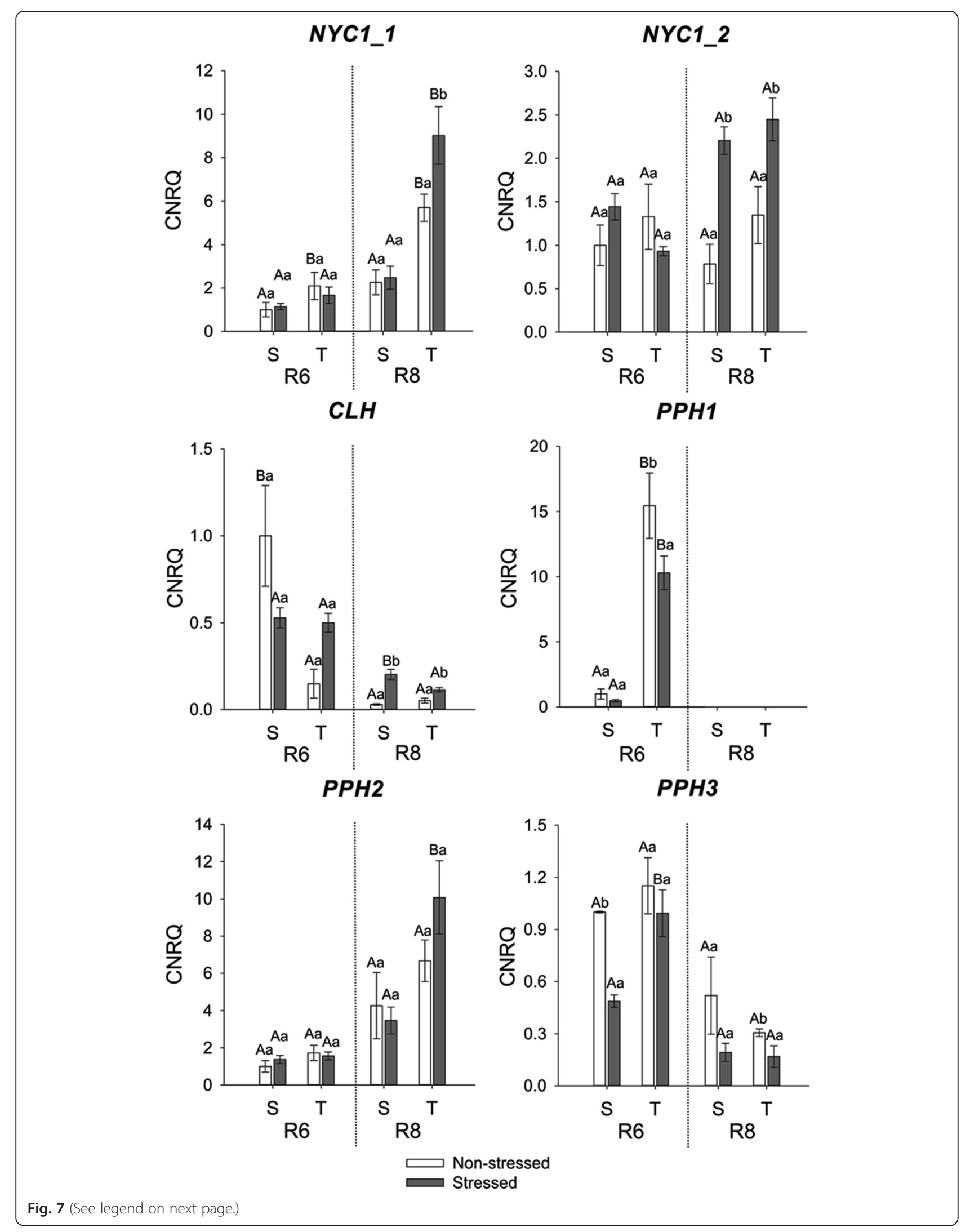


(See figure on previous page.)

Fig. 7 Gene expression analysis by real-time quantitative PCR represented as the calibrated normalized relative quantity (CNRQ) for NYC1_1,

NYC1_2, CLH, PPH1, PPH2 and PPH3. Gene expression is shown for non-stressed (open bars) and stressed seeds (closed bars) of the susceptible (S) and tolerant (T) cultivars in three stages of maturation (R6-R7-R8). Bars represent the mean values \pm SE of three independent biological replicates. Lowercase letters represent statistically significant differences $(P \leq 0.05)$ between different environmental conditions within the same cultivar and developmental stage and uppercase letters between different cultivars within the same environmental condition and developmental stage

the maturation process and it has become a great concern to the soybean market in the last few years $([39,40])$. However, chlorophyll retention in seeds is not unique to Brazil or to soybean as it has been reported in other countries and in canola seeds [2-7, 37, 41-43]. A similar phenotype to chlorophyll retention, called staygreen has been described in leaves and seeds of mutants of different species [44]. Although several of these mutations have been described for the actual SGR gene $[19,21,45]$ there are also mutations described in CCGs resulting in a stay-green phenotype, for example: $P A O$ [46, 47], OsNYC1 [35], AtPPH [22], and OsNYC3 [28].

Although reports of $\mathrm{Chl}$ retention in seeds can be tracked to the early nineties $[6,41]$, the molecular basis of this phenomenon has not yet been unravelled. Using a RT-qPCR approach we demonstrate that combined heat and drought stress affect expression of genes in the Chl degradation pathway, as well as genes encoding Chlbinding proteins in at least one cultivar and/or stage of maturation. Under these stressful environmental conditions the two soybean cultivars also behaved differently regarding the chlorophyll retention phenotype. Based on our results we suggest that impairment of expression of $D 1, D 2, N Y C 1$ 1 and PPH2, is the (downstream) cause of chlorophyll retention in mature soybean seeds of the susceptible cultivar.

\section{How can impaired expression of SGR and CCGs lead to $\mathrm{Chl}$ retention in stressed soybean seeds}

During soybean seed maturation, D1 and D2 displayed very similar patterns of expression (Fig. 9) as has been observed also during leaf senescence [17]. D1 and D2 are two unlinked nuclear loci that have been assumed to be paralogues in tetraploid soybean because homozygosity at both nuclear loci is required for the stay green phenotype, unlike other species in which the mutation of one gene has been shown to be sufficient for the staygreen phenotype [17].

The increase in expression of both genes correlated with chlorophyll degradation during seed maturation and the higher expression of $D 1$ and $D 2$ in stressed seeds of the tolerant cultivar at R8 supported the more efficient Chl degradation of this cultivar even under stressed conditions. However, seeds of the tolerant cultivar also expressed higher levels of both stay-green genes under non-stressed conditions when compared to the susceptible cultivar. This constitutive difference in levels of expression of $S G R$ between the two cultivars may explain the difference in the efficiency of disassembly of the Chl-protein complexes and Chl degradation between the two cultivars under heat and drought stress. Apparently, under normal environmental conditions the higher levels of SGR transcripts in seeds of the susceptible cultivar do not cause phenotypic differences but under stressed environmental conditions it clearly leads to a Chl retention phenotype suggesting cryptic genetic variation between these two genotypes [48, 49].

Besides the importance of SGR in the activation of Chl-protein complex disassembly and, hence, Chldegradation in leaves $[19,21]$, it has been shown that the SGR1 and SGR2 genes are also necessary for seed degreening in Arabidopsis [50]. Interestingly the soybean D1 and D2 genes, which are functional orthologues of SGR in other species, promoted restoration of the wild type phenotype when introduced into the Arabidopsis SGR mutant nye1 [17]. Furthermore, it was recently found that the Arabidopsis SGR1 physically interacts with all six known CCEs (i.e. NOL, NYC1, HCAR, PPH, PAO, and RCCR) and possibly forms a highly dynamic, multi-protein complex for $\mathrm{Chl}$ degradation during natural senescence $[11,51]$.

The transcription of some Chl-degradation genes, especially NYC1 and $P P H$, were shown to be affected by the $d 1 d 2$ mutation in a previous study with soybean [17]. Consistent with this, the expression of $N Y C 1 \_1$ and PPH2, mirrored the expression of D1 and D2 in soybean seeds. In fact, $D 1$ and $D 2$ are highly correlated with expression of $N Y C 1 \_1$ and $P P H 2$, suggesting co-regulation of these genes (Fig. 10). D1, D2, PPH2 and NYC1_1 are the only genes with a significant negative correlation with chlorophyll content (with p-values $0.02,0.02,0.03$ and 0.1 respectively). Therefore we hypothesise that the constitutively higher expression of these four genes aid greater tolerance to heat and drought stress regarding chlorophyll degradation in the seeds during maturation. Future experiments overexpressing these genes in the susceptible cultivar will be needed to test this hypothesis.

Approximately $75 \%$ of the genes are present in more than one copy in the soybean genome [52] due to at least two whole genome duplication (WGD) events within the last 60 million years [53-55]. However, it is hypothesised that functions of duplicated genes can be very divergent [17]. This divergence is well exemplified 
PA01

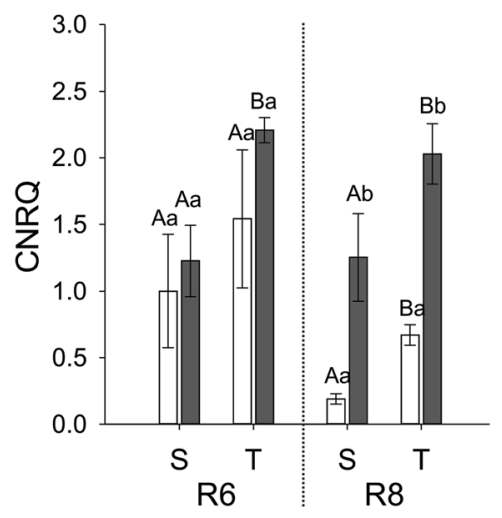

RCCR1

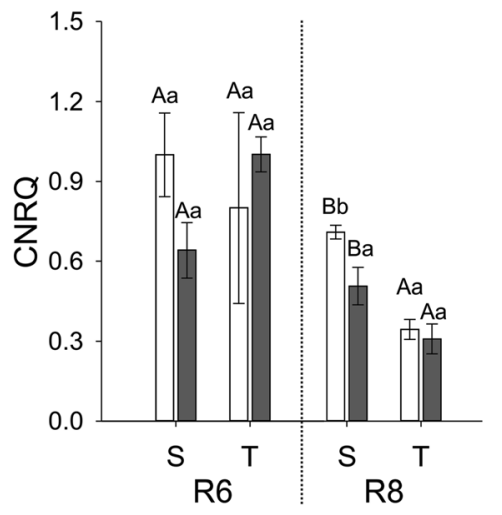

PAO2

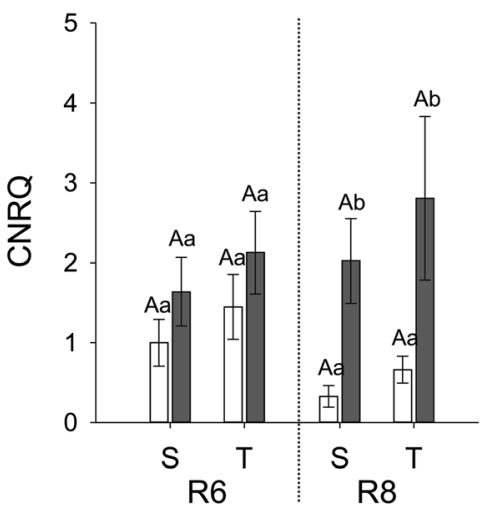

RCCR2

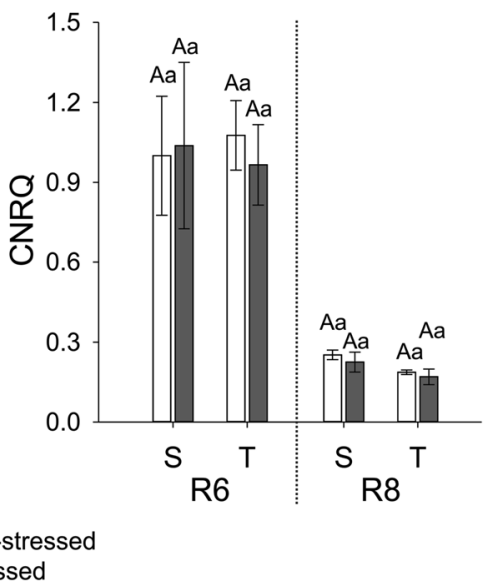

Fig. 8 Gene expression analysis by real-time quantitative PCR represented as the calibrated normalized relative quantity (CNRQ) for PAO1, PAO2, RCCR1 and RCCR2. Gene expression is shown for non-stressed (open bars) and stressed seeds (closed bars) of the susceptible (S) and tolerant (T) cultivars in three stages of maturation (R6-R7-R8). Bars represent the mean values \pm SE of three independent biological replicates. Lowercase letters represent statistically significant differences $(P \leq 0.05)$ between different environmental conditions within the same cultivar and developmental stage and uppercase letters between different cultivars within the same environmental condition and developmental stage

by the terminal flower gene. Among the four homologous genes of Arabidopsis TERMINAL FLOWER (AtTFL1) in soybean, only one has been found to control growth habit whereas the other copies are suggested to have alternative functions as they show divergent transcriptional patterns [56]. This also seems to be the case for the genes involved in seed degreening, especially NYC1_1 and PPH2, which are the only copies that where strongly affected in stressed seeds.

The Chl-binding proteins, on the other hand, correlated positively with the chlorophyll content of the seeds. The disassembly of the photosystems has been consistently reported to be directly related to $\mathrm{Chl}$ degradation during senescence. For example, the breakdown of the LHCs, is crucial for degreening during leaf senescence $[18,57]$, as these peripheral antennas contain most of the Chl. Consequently, retention of LHCs and of core subunits of the PSII have been associated with the stay- green phenotype in some species $[10,11,17,35,58-60]$. The higher expression of $p s b C$ and $p s b B$ observed in mature stressed/green seeds was also reported in the rice stay-green mutant $n y c 4-1$ in which the PSII subunits CP43 and CP47 (encoded by $p s b C$ and $p s b B$ respectively) were more stable than in the wild type during senescence [24].

Under stressful conditions the changes in expression of $p s b A$ and $p s b D$ were different in seeds of the susceptible and tolerant cultivar. However, a possible retention of $\mathrm{D} 1$ protein $(p s b A)$ requires further investigation since this protein has the highest turnover among all the PSII proteins and its abundance can be affected by several processes [61, 62].

Although there are no reports so far about photosystem disassembly in seeds, we expect that the degreening in seeds also depends on the disassembly of LHCs and of other Chl-binding proteins. With the exception 


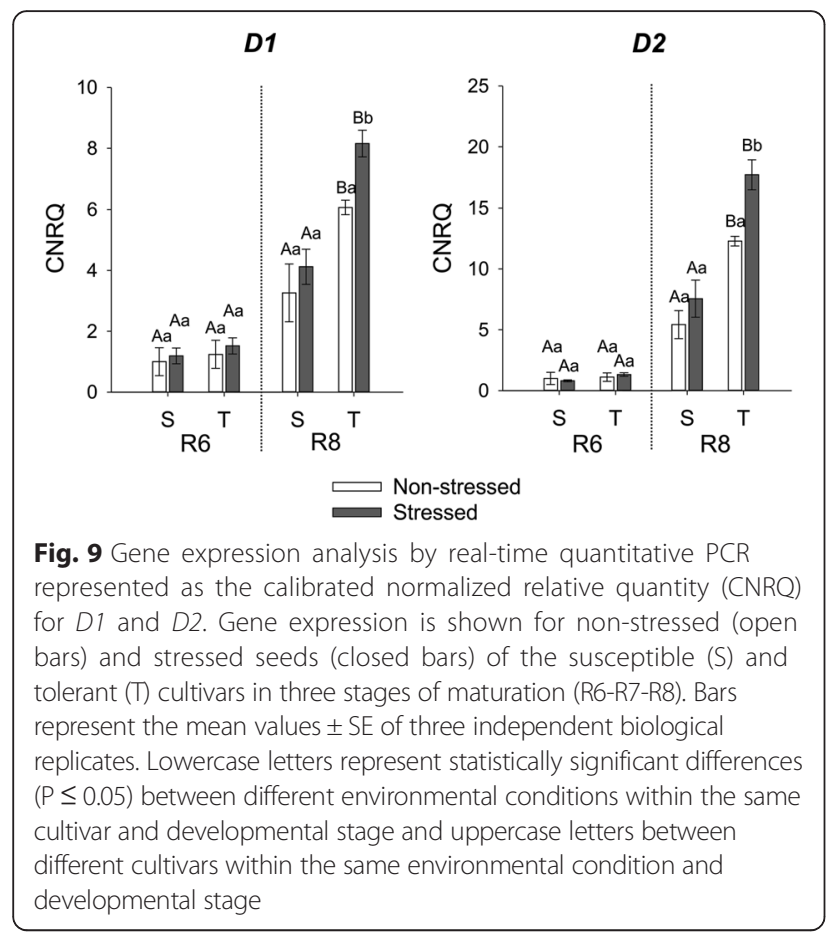

of $p s b A$, which shows constant expression during maturation in stressed seeds of the susceptible cultivar, the pattern of expression of $L H C A, C y t B_{6} F$ and core proteins of PSI and PSII decreased in both non-stressed and stressed seeds during maturation. This mostly reflects the normal disassembly of the photosynthetic apparatus during the maturation process that follows Chl degradation.

The role of SGR genes as regulators of chlorophyll degradation during developmental and dark-induced senescence is well established in leaves and more recently the role of these genes in embryo degreening has been described [50]. During Arabidopsis leaf senescence SGR1 and SGR2 act antagonistically in the control of Chl degradation [63], while in seeds they act synergistically $[17,50]$. Although there has been great progress in understanding chlorophyll degradation in higher plants over the last few years, the seed degreening process still awaits to be resolved. Studying in vitro interactions between SGR, Chl-binding proteins and CCEs may possibly elucidate some aspects of $\mathrm{Chl}$ degradation during seed ripening.

\section{Conclusion}

The combination of heat and drought stress during late seed maturation resulted in a "mild" stay-green phenotype and impaired expression of SGR 1 and $2(D 1, D 2)$, $P P H 2$ and $N Y C 1 \_1$ in soybean seeds of a susceptible soybean cultivar. This may be a case of cryptic genetic variation between these two genotypes as the genetic variation itself does not lead to chlorophyll retention under normal environmental conditions, but under combined heat and drought stress a clear green phenotype is observed in seeds of the susceptible cultivar. In other words we suggest that the constitutively higher expression of these four genes in fully mature seeds of the tolerant cultivar allows these seeds to cope with stressful

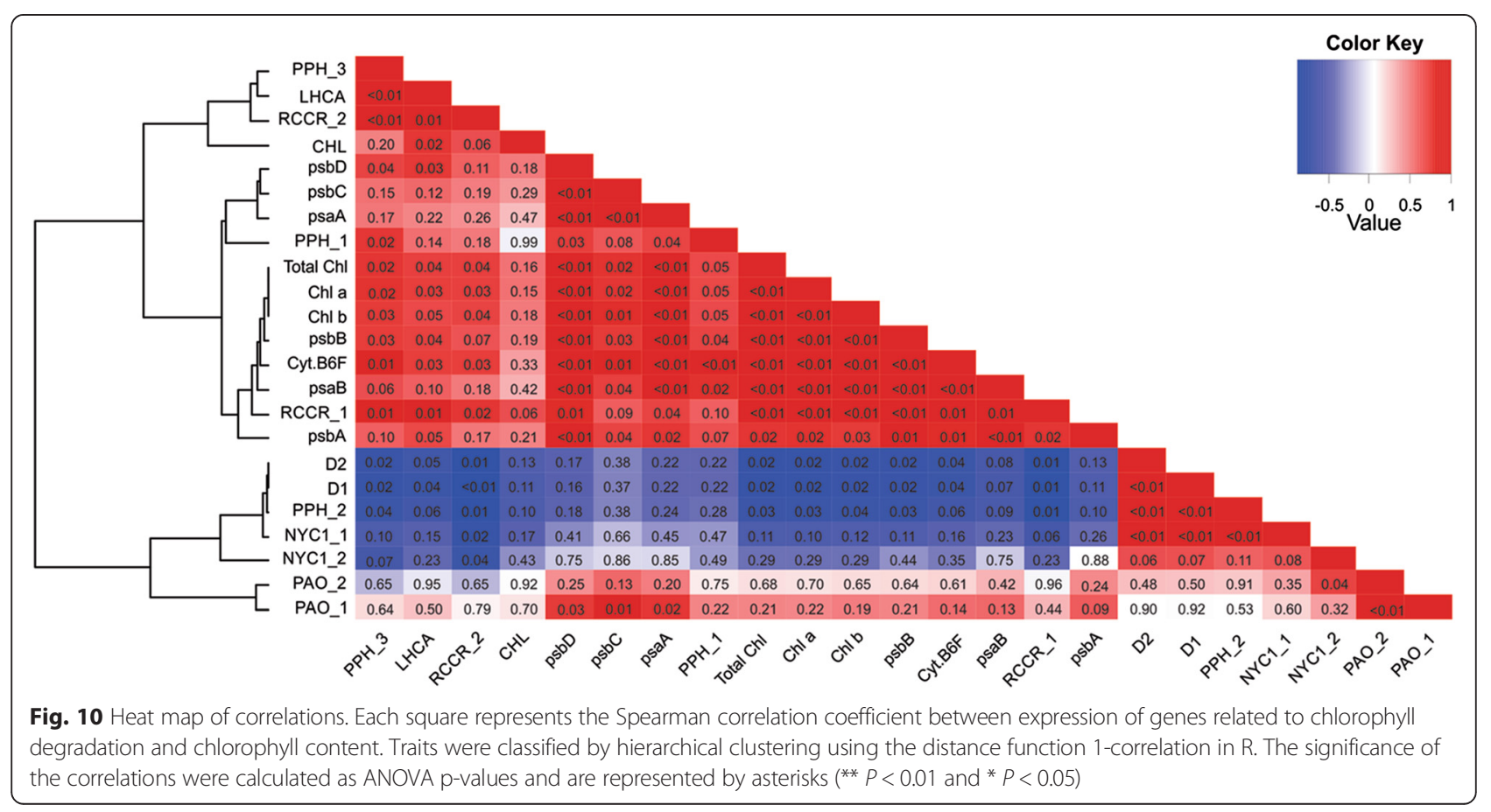


conditions and complete chlorophyll degradation. The results described here deepen our understanding of chlorophyll retention in soybean seeds. The insights gained from this research will pave the way for new research ultimately providing direction to breeding programs aiming to produce tolerant cultivars. This is particularly pertinent as the hot and dry climate conditions which cause chlorophyll retention are increasingly common in the largest soybean production areas of the world and as a result there is an increasing need for resistant germplasm.

\section{Methods}

\section{Plant material and growth conditions}

Two cultivars of soybean were used to produce the seeds in this study. The cultivar MG/BR 46-Conquista (BRA093483/CENARGEN) (late cycle) was used as susceptible to Chl retention and the cultivar BRS 133 (BRA097934/CENARGEN) (semi-early cycle) was used as the tolerant genotype [9].

During the vegetative phase both cultivars were grown in a polytunnel, subjected to the local environmental conditions (Botucatu, SP - Brazil, 2013) (Additional file 1: Figure S1 and Figure S2). During this phase the climatic conditions of this region could be considered as non-stressed with an average temperature of $24.7{ }^{\circ} \mathrm{C}$. The plants received a free water supplement (field capacity). At R5.5 (Additional file 1: Figure S3) part of the pots were maintained under these non-stressed conditions and part was transferred to a greenhouse (Van der Hoeven, Brazil) with an average day temperature of $39.5{ }^{\circ} \mathrm{C}$ for the susceptible cultivar and $38.7^{\circ} \mathrm{C}$ for the tolerant one (Additional file 1: Figure S1 and Figure S2). The plants in stressed conditions were only watered when wilting was observed. At these moments plants were watered to bring the soil to field capacity.

\section{Sampling points}

The seeds were harvested at three stages of maturation (R6, R7 and R8) solely based on plant and pod characteristics (Additional file 1: Table S1). At each stage the four plants in the pot (six pots) were cut and the pods were removed. A post-harvest selection based on seed colour (Additional file 1: Figure S4) was done in order to reduce variability in maturation between seeds of the same sample.

Combining the environmental conditions (non-stressed and stressed) and the harvesting points (R6-R7-R8), there were six different seed samples for each cultivar and six replicates. The six replicates of each sample were grouped two by two to constitute three biological replicates. The appearance of the pods and seeds constituting nonstressed samples in each of the three stages of maturation is displayed in Figure S4 (Additional file 1).

\section{Chl quantification}

Samples were lyophilized and ground to a powder for the quantification of $\mathrm{Chl} a$ and $b$ by high performance liquid chromatography (HPLC). Both Chl $a$ and $b$ standards were purchased from Sigma (USA). All the solvents used were HPLC grade.

Extraction of Chls was performed under green light according to SS Teng and BH Chen [64] with adaptations. Ground seed samples of 0.5 to $2 \mathrm{~g}$ were placed in a $50 \mathrm{ml}$ Falcon tube, to which $5 \mathrm{ml}$ of methanol was added. The mixture was homogenized with a homogenizer for 30s and centrifuged at $3000 \mathrm{~g}\left(4^{\circ} \mathrm{C}\right)$ for $3 \mathrm{~min}$. The supernatant was collected in a new Falcon tube. In a second step the same procedure was repeated with acetone, and this was repeated several times until the extract became colourless. All the methanol/acetone extracts were pooled and brought to a volume of 25 or $50 \mathrm{ml}$ with the addition of methanol and the solution was filtered through a $0.2 \mu \mathrm{m}$ membrane filter for HPLC and placed in an amber vial for immediate subsequent injection. The extraction of Chls was done in a ratio of 1:100 (w/v) for R6 samples (intense green), 1:50 (w/v) for R7 samples (light green) and 1:12.5 (w/v) for R8 samples depending on the intensity of the pigment colour (Chl concentration).

Analytical separations were performed on a Shimadzu Shim-Pack VP-ODS column $(150$ x $2.0 \mathrm{~mm}$ - serial number 6102708). Pigments were eluted using a linear gradient in $15 \mathrm{~min}$, with a two-solvent system: methanol:ammonium acetate $(80: 20 \mathrm{v} / \mathrm{v})$ and methanol:acetone $(80: 20 \mathrm{v} / \mathrm{v})$. The injection volume was $25 \mu \mathrm{l}$. The fluorescence detector (Shimadzu RF-10XL) was operated at an excitation of $440 \mathrm{~nm}$, an emission of $660 \mathrm{~nm}$ and a flow rate of $0.8 \mathrm{ml} / \mathrm{min}$ [65].

Calibration curves were made from 0.01 to $5.0 \mathrm{mg} / \mathrm{l}$ for both Chls. High linearity was obtained with correlation coefficients of 0.99 . Chl $a$ and $b$ were then quantified using the respective calibration curves.

\section{RNA extraction and CDNA synthesis}

Total RNA extraction was performed with the NucleoSpin ${ }^{\circ}$ RNA Plant kit (Macherey-Nagel) according to the manufacture's protocol in three biological replicates with at least 15 seeds of each biological sample. RNA integrity was assessed by analysis on a $1 \%$ agarose gel and RNA sample quality and concentration were additionally assessed using a Nanodrop ND-1000 (Thermo Scientific). cDNA was then synthesized using the HighCapacity cDNA Reverse Transcription Kit (Applied Biosystems) according to the manufacture's protocol.

\section{Microarray analysis}

For the microarray analysis, three biological replicates of total RNA from seed samples of the susceptible cultivar 
(MG/BR 46) were used. After cDNA synthesis, according to the Affymetrix protocol (Affymetrix ${ }^{\circ}$, GeneChip ${ }^{\circ}$ 3'IVT Express Kit user manual), the samples were hybridized to Affymetrix microarrays (Soybean Genome GeneChip Array). In total 18 arrays were used (3 stages of maturation X 2 environmental conditions X 3 replicates, GEO Series ID GSE70999).

Quality control and pre-processing analysis of the microarray results was done using a tool of the open source package ArrayAnalysis.org that is freely available from http://www.arrayanalysis.org [66]. After normalization and background removal, data was filtered to keep probe sets with a signal above expression value 3 in at least one of the conditions analysed.

To get a shorter list of candidate genes related to stress and thus Chl retention in soybean seeds we used R. Data was corrected for multiple testing (FDR). A 2fold change and significant level of $0.05(p$-value $\leq 0.05)$ were used for filtering.

\section{Quantitative PCR (RT-qPCR) analysis}

iQ-SYBR Green-Supermix (Bio-Rad) was used for gene expression analysis on a MyIQ RT-qPCR machine (BioRad) and Lumino Ct SYBR Green RT-qPCR Ready Mix (Sigma) for the analysis on an Eco Real-Time PCR system (Illumina).

The RT-qPCR program for both machines consisted of a first step at $95{ }^{\circ} \mathrm{C}$ for $3 \mathrm{~min}$, followed by 40 cycles of $15 \mathrm{~s}$ at $95{ }^{\circ} \mathrm{C}$ and $1 \mathrm{~min}$ at $60{ }^{\circ} \mathrm{C}$. The primers used (Additional file 1: Tables S2 and Table S3) were preferably designed in the 3' end of the transcript and, if possible, spanning an intron-exon border. The Tm of the primers was between 58 and $62{ }^{\circ} \mathrm{C}$ except a few primers with slightly lower $\mathrm{Tm}$. Routinely a melting curve analysis was performed after the RT-qPCR run (between 55 and $95{ }^{\circ} \mathrm{C}$ with $0.5{ }^{\circ} \mathrm{C}$ increments each $10 \mathrm{~s}$ ). For all primers, a single peak was observed, confirming the synthesis of a single product.

Primer efficiency was calculated performing a 10X dilution series and the slope of the standard curve was translated into an efficiency value. All primers showed efficiencies between 90 and $110 \%$. Ct values were analysed in an excel sheet using a normalization factor calculation based on the geometric mean of multiple control genes proposed by J Vandesompele, Kd Pretter, F Pattyn, B Poppe, NV Roy, Ad Paepe and F Speleman [67]. RTqPCR data of each gene of interest were normalized against the two most stable reference genes, chosen as described below. The list of target genes analysed in this study can be found in Additional file 1: Table S2.

\section{Reference gene identification}

The identification of new reference genes, suitable for normalization of RT-qPCR data, was done based on microarray data. The most stable transcripts were selected based on the datasets from three microarray experiments: this study, KA Hudson [68] and T Asakura, T Tamura, K Terauchi, T Narikawa, K Yagasaki, Y Ishimaru and K Abe [69] (GEO Series ID GSE70999, GSE18827 and GSE26443, respectively).

The expression of the selected genes was analysed by RT-qPCR and their stability was calculated by geNORM [67]. Two genes (Prot and 60S) displayed $M$ values lower than 0.5 (Additional file 1: Figure S5) and were used for RT-qPCR expression data normalization in this study.

\section{Statistical analysis}

An ANOVA test was performed on the percentage of green seeds, Chl content and gene expression data at the significance level of $5 \%(p \leq 0.05)$. A factorial $2 \times 2$ setup ( 2 cultivars X 2 environmental conditions) was used and the analysis was done for each stage of maturation individually. The averages were compared by $\mathrm{T}$ test at $5 \%$ probability level.

\section{Correlation analysis}

Correlation analysis was performed between the expression of 20 genes and chlorophyll content in the seeds. The heat map was constructed using the Spearman correlation coefficient matrices R-packages "MASS", "Hmisc" and "VGAM" and the R graphic packages "gplots" and "graphics" were used for visualizing the data.

\section{Availability of supporting data}

The data set supporting the results of this article is available in the NCBI's GEO dataset (http://www.ncbi.nlm. nih.gov/gds) under the series ID GSE70999.

\section{Additional file}

Additional file 1: Table S1. Description of the vegetative and reproductive stages of soybean (RITCHIE et al., 1982). Table S2. Sequences of the primers used for the target gene study. Table S3. Sequences of the primers used for the analysis of reference genes. Figure S1. Average temperatures and relative humidity during the life cycle of the susceptible cultivar under non-stressed and stressed conditions. Figure S2. Average temperatures and relative humidity during the life cycle of the tolerant cultivar under non-stressed and stressed conditions. Figure S3. Progression of seed development in the stage of maturation R5 (R5.3; R5.4; R5.5), cultivar MG/BR 46. The black bar represents $1 \mathrm{~cm}$. Figure S4. Pod and seed characteristics at the reproductive stages R6, R7 and R8, cultivar MG/BR 46. The black bar represents $1 \mathrm{~cm}$. (PDF $1714 \mathrm{~kb}$ )

\section{Abbreviations}

CCE: chlorophyll catabolic enzyme; CCG: chlorophyll catabolic gene; Chl: chlorophyll; CLH: chlorophyllase; HCAR: hydroxyl-methyl chlorophyll a reductase; HPLC: high performance liquid chromatography; LHC: light harvesting complex; NOL: non-yellow coloring like; NYC: non-yellow coloring; PAO: pheophorbide a oxigenase; Pheide: pheophorbide; Phein: pheophytin; PPH: pheophytinase; PSI: photosystem I; PSII: photosystem II; RCC: red 
chlorophyll catabolite; RCCR: red chlorophyll catabolite reductase; SGR: staygreen.

\section{Competing interests}

The authors declare that they have no competing interests.

\section{Authors' contribution}

RNT conceived and designed the study, carried out all the experiments, performed data interpretation and analysis and wrote the manuscript. WL participated in the coordination of the study, assisted in the microarray- and statistical analysis and provided critical reading of the manuscript. JBFN participated in the conceiving of the study and provided seed material for the experiments. HWMH participated in the coordination of the study and discussions on data interpretation and contributed with critical reading of the manuscript. EAAS participated in the design of the study, coordination and critical reading of the manuscript. All authors read and approved the final manuscript.

\section{Acknowledgments}

The authors would like to thank Embrapa Soja for providing seed material. We also thank the technician and PhD students of the Seed Lab of UNESPBotucatu for help with harvesting, Alexandre C. S. S. Marques for photo editing and Padraic Flood for feedback on the manuscript. This work was supported by FAPESP (Auxilio regular à pesquisa 2010/20263-8, Bolsa de doutorado no país 2010/19878-8 and Bolsa de estágio pesquisa no exterior BEPE 2012/09453-5). The authors declare no conflicts of interest.

\section{Author details}

'Wageningen Seed Lab, Laboratory of Plant Physiology, Wageningen University, Droevendaalsesteeg 1, Wageningen 6708 PB, The Netherlands. ${ }^{2}$ Departamento de Produção e Melhoramento Vegetal, Faculdade de Ciências Agronômicas-UNESP, Universidade Estadual Paulista, Botucatu, SP 18.610-307, Brazil. ${ }^{3}$ Empresa Brasileira de Pesquisa Agropecuária, Centro Nacional de Pesquisa de Soja, EMBRAPA Soja, Caixa-postal 231, Londrina, PR 86001970, Brazil.

\section{Received: 12 October 2015 Accepted: 28 January 2016}

\section{Published online: 01 February 2016}

\section{References}

1. Pádua GP, França Neto JB, Carvalho MLM, Costa O, Krzyzanowski FC, Costa NP. Tolerance level of green seed in soybean seed lots after storage. Rev Bras Sementes. 2007;29(3):112-20.

2. Pádua GP, França Neto JB, Carvalho MLM, Krzyzanowski FC, Guimarães RM. Incidence of green soybean seeds as a function of environmental stresses during seed maturation. Rev Bras Sementes. 2009;31(3):150-9.

3. Zoratto MF, Peske ST, Takeda C, França Neto JB. Presença de sementes esverdeadas em soja e seus efeitos sobre seu potencial fisiológico. Rev Bras Sementes. 2007;29(1):11-7.

4. Mailer RJ, Orchard B, Vonarx MM, Wratten N. Influence of cultivar and environment on the chlrorophyll concentration of Australian canola seed. Aust J Exp Agric. 2003;43:169-76.

5. Chung DW, Pruzinska A, Hortensteiner S, Ort DR. The role of pheophorbide a oxygenase expression and activity in the canola green seed problem. Plant Physiol. 2006;142(1):88-97.

6. Johnson-Flanagan AM, Thiagarajah MR. Degreening in canola (Brassica napus, cv. Westar) embryos under optimum conditions. J Plant Physiol. 1990;136:180-6.

7. Green BR, Singh S, Babic I, Bladen C, Johnson-Flanagan AM. Relashionship of chlorophyll, seed moisture and ABA levels in the maturing Brassica napus seed and effect of a mild freezing stress. Physiol Plant. 1998;104:125-33.

8. CONAB. Acompanhamento da Safra Brasileira de Grãos. In., vol. 1, 10/2015 edn. http://www.conab.gov.br/conteudos. php?a=1253\&ordem=criterioSafra1: CONAB; 2015.

9. Pádua GP, Carvalho MLM, França Neto JB, Guerreiro MC, Guimarães RM. Response of soybean genotypes to the expression of green seed under temperature and water stresses. Rev Bras Sementes. 2009;31(3):140-9.

10. Hörtensteiner S. Update on the biochemistry of chlorophyll breakdown. Plant Mol Biol. 2013;82(6):505-17.

11. Sakuraba Y, Schelbert S, Park SY, Han SH, Lee BD, Andres CB, et al. STAYGREEN and chlorophyll catabolic enzymes interact at light-harvesting complex II for chlorophyll detoxification during leaf senescence in Arabidopsis. Plant Cell. 2012;24(2):507-18.

12. Tanaka R, Tanaka A. Chlorophyll cycle regulates the construction and destruction of the light-harvesting complexes. Biochim Biophys Acta. 2011; 1807(8):968-76.

13. Clerkx EJ, Vries HB, Ruys GJ, Groot SP, Koornneef M. Characterization of green seed, an enhancer of abi3-1 in Arabidopsis that affects seed longevity. Plant Physiol. 2003;132(2):1077-84.

14. Pruzinska A, Tanner G, Anders I, Roca M, Hortensteiner S. Chlorophyll breakdown: pheophorbide a oxygenase is a Rieske-type iron-sulfur protein, encoded by the accelerated cell death 1 gene. Proc Natl Acad Sci USA. 2003;100(25):15259-64.

15. Tanaka R, Hirashima M, Satoh S, Tanaka A. The Arabidopsis-accelerated cell death gene ACD1 is involved in oxygenation of pheophorbide a: inhibition of pheophorbide a activity does not lead to the "stay-gree"phenotype in Arabidopsis. Plant Cell Physiol. 2003;44(12):1266-74.

16. Park SY, Yu JW, Park JS, Li J, Yoo SC, Lee NY, et al. The senescence-induced staygreen protein regulates chlorophyll degradation. Plant Cell. 2007;19(5): 1649-64.

17. Fang C, Li C, Li W, Wang Z, Zhou Z, Shen Y, et al. Concerted evolution of D1 and D2 to regulate chlorophyll degradation in soybean. Plant J. 2014; 77(5):700-12.

18. Horie Y, Ito H, Kusaba M, Tanaka R, Tanaka A. Participation of chlorophyll $b$ reductase in the initial step of the degradation of light-harvesting chlorophyll a/b-protein complexes in Arabidopsis. J Biol Chem. 2009;284(26):17449-56.

19. Ren G, An K, Liao Y, Zhou X, Cao Y, Zhao H, et al. Identification of a novel chloroplast protein AtNYE1 regulating chlorophyll degradation during leaf senescence in Arabidopsis. Plant Physiol. 2007;144(3):1429-41.

20. Sato Y, Morita R, Katsuma S, Nishimura M, Tanaka A, Kusaba M. Two shortchain dehydrogenase/reductases, NON-YELLOW COLORING 1 and NYC1LIKE, are required for chlorophyll b and light-harvesting complex II degradation during senescence in rice. Plant J. 2009;57(1):120-31.

21. Sato Y, Morita R, Nishimura M, Yamaguchi H, Kusaba M. Mendel's green cotyledon gene encodes a positive regulator of the chlorophyll-degrading pathway. Proc Natl Acad Sci USA. 2007;104(35):14169-74.

22. Schelbert S, Aubry S, Burla B, Agne B, Kessler F, Krupinska K, et al. Pheophytin pheophorbide hydrolase (pheophytinase) is involved in chlorophyll breakdown during leaf senescence in Arabidopsis. Plant Cell. 2009;21(3):767-85

23. Wu Z, Zhang X, He B, Diao L, Sheng S, Wang J, et al. A chlorophyll-deficient rice mutant with impaired chlorophyllide esterification in chlorophyll biosynthesis. Plant Physiol. 2007;145(1):29-40.

24. Yamatani H, Sato Y, Masuda Y, Kato Y, Morita R, Fukunaga K, et al. NYC4, the rice ortholog of Arabidopsis THF1, is involved in the degradation of chlorophyll - protein complexes during leaf senescence. Plant J. 2013;74(4):652-62.

25. Zhou C, Han L, Pislariu C, Nakashima J, Fu C, Jiang Q, et al. From model to crop: functional analysis of a STAY-GREEN gene in the model legume Medicago truncatula and effective use of the gene for alfalfa improvement. Plant Physiol. 2011;157(3):1483-96.

26. Hörtensteiner S, Kräutler B. Chlorophyll breakdown in higher plants. Biochim Biophys Acta. 2011;1807(8):977-88.

27. Scheumann V, Schoch S, Rüdiger W. Chlorophyll a formation in the chlorophyll $b$ reductase reaction requires reduced ferredoxin. J Biol Chem. 1998;273(52):35102-8.

28. Morita R, Sato $Y$, Masuda $Y$, Nishimura M, Kusaba M. Defect in nonyellow coloring 3 , an alpha/beta hydrolase-fold family protein, causes a stay-green phenotype during leaf senescence in rice. Plant J. 2009;59(6): 940-52.

29. Pruzinská A, Andrers I, Aubry S, Schenk N, Tapernoux-Lüthi E, Müller T, et al. In vivo participation of red chlorophyll catabolite reductase in chlorophyll breakdown. Plant Cell. 2007;19:369-87.

30. Barry CS. The stay-green revolution: Recent progress in deciphering the mechanisms of chlorophyll degradation in higher plants. Plant Sci. 2009; 176(3):325-33.

31. Gomes MSO, Sinnecker P, Tanaka RT, Lanfer-Marquez UM. Effects of harvesting and drying conditions on chlorophyll levels of soybean (Glycine max L. Merr). J Agric Food Chem. 2003;51:1634-9.

32. Sinnecker $\mathrm{P}$, Braga N, Macchione ELA, Lanfer-Marquez UM. Mechanism of soybean (Glycine max L. Merrill) degreening related to maturity stage and postharvest drying temperature. Postharvest Biol Technol. 2005;38(3):269-79 
33. Ritchie SW, Hanway JJ, Thompson HE. How a Soybean Plant Develops. In: Special Report n53. Ames lowa: lowa State University of Science and Technology: Cooperative Extension Service; 1982. p. 1-20.

34. Joosen RVL, Ligterink W, Dekkers BJW, Hilhorst HWM. Visualization of molecular processes associated with seed dormancy and germination using MapMan. Seed Sci Res. 2011;21(02):143-52.

35. Kusaba M, Ito H, Morita R, lida S, Sato Y, Fujimoto M, et al. Rice NONYELLOW COLORING1 is involved in light-harvesting complex II and grana degradation during leaf senescence. Plant Cell. 2007;19(4):1362-75.

36. Takamiya K, Tsuchiya T, Ohta H. Degradation pathway(s) of chlorophyll: what has gene cloning revealed? Trends Plant Sci. 2000;5(10):426-31.

37. Daun JK. How green is green? Long term relationships between green seeds and chlorophyll in canola grading. J Am Oil Chem Soc. 2003;80(2): 119-22.

38. Schenk N, Schelbert S, Kanwischer M, Goldschmidt EE, Dormann P, Hortensteiner S. The chlorophyllases AtCLH1 and AtCLH2 are not essential for senescence-related chlorophyll breakdown in Arabidopsis thaliana. FEBS Lett. 2007;581(28):5517-25.

39. Mendes R. Soja verde é um sério problema. 2014. Retrieved June 30, 2015 from Revista Rural website: http://www.revistarural.com.br/edicoes/item/ 5959-soja-verde-\%C3\%A9-um-s\%C3\%A9rio-problema.

40. Patroni L. Grãos de soja esverdeados preocupam produtores em MS. 2014. Retrieved August 19, 2015 from Canal Rural website: http://www.canalrural. com.br/noticias/agricultura/graos-soja-esverdeados-preocupam-produtores47112.

41. Ward K, Scarth R, Daun JK, Vessey JK. Chlorophyll degradation in summer oilseed rape and summer turnip rape during seed ripening. Can J Plant Sci. 1995;75:413-20

42. Costa NP, França-Net JB, Pereira JE, Mesquita CM, Krzyzanowski FC, Henning AA. Green seeds effect on the physiological quality of soybean seeds. Rev Bras Sementes. 2001;23(2):107-7.

43. Cicero SM, Schoor R, Jalink $H$. Use of chlorophyll fluorescence sorting to improve soybean seed quality. Rev Bras Sementes. 2009;31(4):145-51.

44. Thomas H, Ougham H. The stay-green trait. J Exp Bot. 2014;65(14):3889-900.

45. Jiang $H$, Li M, Liang N, Yan H, Wei Y, Xu X, et al. Molecular cloning and function analysis of the stay green gene in rice. Plant J. 2007:52:197-209.

46. Thomas H. Sid: a Mendelian locus controling thylakoid membrane disassembly in senescing leaves of Festuca pratensis. Theor Appl Genet. 1987;73:551-5

47. Thomas H, Morgan WG, Thomas AM, Ougham HJ. Expression of the stay-green character introgressed into Lolium temulentum Ceres from a senescence mutant of Festuca pratensis. Theor Appl Genet. 1999;99:92-9.

48. Paaby AB, Rockman MV. Cryptic genetic variation: evolution's hidden substrate. Nat Rev Genet. 2014;15(4):247-58.

49. Gibson G, Dworkin I. Uncovering cryptic genetic variation. Nat Rev Genet. 2004:5(9):681-90.

50. Delmas F, Sankaranarayanan S, Deb S, Widdup E, Bournonville C, Bollier N, et al. ABI3 controls embryo degreening through Mendel's / locus. Proc Natl Acad Sci USA. 2013.

51. Sakuraba Y, Kim YS, Yoo SC, Hortensteiner S, Paek NC. 7-Hydroxymethyl chlorophyll a reductase functions in metabolic channeling of chlorophyl breakdown intermediates during leaf senescence. Biochem Biophys Res Commun. 2013;430(1):32-7.

52. Schmutz J, Cannon SB, Schlueter J, Ma J, Mitros T, Nelson W, et al. Genome sequence of the palaeopolyploid soybean. Nature. 2010;463(7278):178-83.

53. Shoemaker RC, Schlueter J, Doyle JJ. Paleopolyploidy and gene duplication in soybean and other legumes. Curr Opin Plant Biol. 2006;9(2):104-9.

54. Schlueter JA, Lin JY, Schlueter SD, Vasylenko-Sanders IF, Deshpande S, Yi J, et al. Gene duplication and paleopolyploidy in soybean and the implications for whole genome sequencing. BMC Genomics. 2007:8:330.

55. Chan C, Qi X, Li MW, Wong FL, Lam HM. Recent developments of genomic research in soybean. J Genet Genomics. 2012;39(7):317-24.

56. Tian Z, Wnag S, Lee R, Li Y, Specht JE, Nelson RL, et al. Artificial selection for determinate growth habit in soybean. Proc Natl Acad Sci U S A. 2010; 107(19):8563-8.

57. Consoli E, Croce R, Dunlap DD, Finzi L. Diffusion of light-harvesting complex II in the thylakoid membranes. EMBO reports. 2005;6(8):782-6.

58. Guiamét JJ, Schwartz E, Pichersky E, Noodén LD. Characterization of cytoplasmic and nuclear mutations affecting chlorophyll and chlorophyll binding proteins during senescence in soybean. Plant Physiol. 1991;96:227-31.
59. Grassl J, Pruzinska A, Hortensteiner S, Taylor NL, Millar AH. Early events in plastid protein degradation in stay-green Arabidopsis reveal differential regulation beyond the retention of $\mathrm{LHCll}$ and chlorophyll. J Proteome Res. 2012:11(11):5443-52.

60. Kusaba M, Tanaka A, Tanaka R. Stay-green plants: what do they tell us about the molecular mechanism of leaf senescence. Photosynthesis Res. 2013: 117(1-3):221-34

61. Giardi MT, Masojídek J, Godde D. Effects of abiotic stress on the turnover of the D1 reaction centre II protein. Physiol Plant. 1997;101:635-42.

62. Nickelsen J, Rengstl B. Photosystem II assembly: from cyanobacteria to plants. Annu Rev Plant Biol. 2013:64:609-35.

63. Sakuraba Y, Park SY, Kim YS, Wang SH, Yoo SC, Hortensteiner S, et al. Arabidopsis STAY-GREEN2 is a negative regulator of chlorophyll degradation during leaf senescence. Mol Plant. 2014;7(8):1288-302.

64. Teng SS, Chen BH. Formation of pyrochlorophylls and their derivatives in spinach leaves during heating. Food Chem. 1999;65:367-73.

65. Almela L, Fernández-López JA, Roca MJ. High-performance liquid chromatographic screening of chlorophyll derivatives produced during fruit storage. J Chromatogr. 2000;870:483-9.

66. Eijssen LM, Jaillard M, Adriaens ME, Gaj S, de Groot PJ, Muller M, et al. User-friendly solutions for microarray quality control and pre-processing on ArrayAnalysis.org. Nucleic Acids Res. 2013:41(Web Server issue):W71-76.

67. Vandesompele J, Pretter K, Pattyn F, Poppe B, Roy NV, Paepe A, et al. Accurate normalization of real-time quantitative RT-PCR data by geometric averaging of multiple internal control genes. Genome Biol. 2002;3(7):1-12.

68. Hudson KA. The circadian clock-controlled transcriptome of developing soybean seeds. The Plant Genome. 2010;3(1):1-13.

69. Asakura T, Tamura T, Terauchi K, Narikawa T, Yagasaki K, Ishimaru Y, et al. Global gene expression profiles in developing soybean seeds. Plant Physiol Biochem. 2012;52:147-53.

\section{Submit your next manuscript to BioMed Central and we will help you at every step:}

- We accept pre-submission inquiries

- Our selector tool helps you to find the most relevant journal

- We provide round the clock customer support

- Convenient online submission

- Thorough peer review

- Inclusion in PubMed and all major indexing services

- Maximum visibility for your research

Submit your manuscript at www.biomedcentral.com/submit 